\title{
Neurobehavioral and hepatic complications induced by acute inhalation exposure to abamectin in female rats of the Wistar strain treated with ginger (Zingiber officinale)
}

\author{
Ines Refes $^{a^{*}}$ (i) | Abdelkrim Tahraoui ${ }^{\mathrm{a}}$ (iD) Samir Djemli ${ }^{\mathrm{a}}$ (D) | Mabrouk Boussena ${ }^{\mathrm{a}}$ (D) |

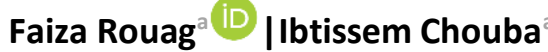

Applied Neuroendocrinology Laboratory, Department of Biology, Faculty of Science, University Badji Mokhtar, Annaba, Algeria.

Corresponding author: ineess23000@outlook.fr

\begin{abstract}
The study we conducted aimed to evaluate the acute toxicity of abamectin (ABM) (pesticide) on liver function and neurobehavioral by using the open field test. As a therapy, we have opted for a treatment based on natural antioxidants ginger extract (Zingiber officinale) mixed with olive oil to see the restorative effects during the experiment. The study was conducted on female Wistar rats. The latter was given an inhalation exposure of abamectin $(A B M)$ at a dose $C L_{50}>5.04$ $\mathrm{mg} / \mathrm{L} / 1 \mathrm{hr}$ each morning for one week. The effects of this exposure showed a drop in body weight gain (g), a significant decrease in the relative and absolute weights liver (gm/100 gm body weight) accompanied by hepatic impairment indicating a significant disturbance of transaminases (AST/ALT), alkaline phosphatase (ALP) activity and significant behavioral changes. Administration of ginger (Zingiber officinale) extract at a dose of $3 \mathrm{ml}$ mixed with olive oil at a dose of $1 \mathrm{ml} / \mathrm{kg}$ for 7 days orally (gavages) after inhalation indicates that ginger has a more remarkable and rapid effect on physical and mental health, it acts as a major means of defense and hepato-protective against toxicity.
\end{abstract}

Keywords abamectin, anxiety, ginger extract, hepatotoxicity, liver parameters

\section{Introduction}

Most pesticides are agricultural chemicals used to destroy pests, weeds, and plant pathogens. These products can be extracted from plants or obtained by synthesis (WHO 1991). They are usually used in aerosols, mists, or gases (Samuel and Saint-Laurent 2001). The synthetic insecticides currently in use are classified into chemical families: organochlorines, organophosphorus, and carbamates. (Bluzat and Seuge 1970). The most widely used insecticide in Algeria is Abamectin (ABM) (Khaldoun-Oularbi et al 2013). It is composed of avermectin B ( $\min .80 \%$ ) and avermectin B (max. 20\%). This mixture belonging to the avermectin family is an active ingredient in plant protection products as an acaricide, an insecticide to treat aerial parts of fruit trees and vegetables (Jargot $D$ et al 2013). The avermectins are a family of macrocyclic lactones produced by the soil organism Streptomyces avermitili (Lasota and Dybas 1990). The residues of pesticides, including their metabolites and/or degradation products, will remain in plants or soil that becomes a significant source of contamination for herbal medicines, which impose serious health risks to human health. According to The World Health Organization (WHO) estimates that $65 \%-80 \%$ of the world's population depend on herbal products as their primary form of health care (Shaban et al 2016).
Phytotherapy is the art of using plants to heal ourselves. It has been used for thousands of years as a source of biologically active therapeutic substances for industrial and agricultural purposes (Niroumand et al 2016). It comes from the Greek words "phyton" meaning plant and "therapein" meaning to heal. It is therefore an allopathic therapy intended to prevent and treat functional disorders and benign pathological states with medicinal plants devoid of toxicity under normal conditions of use (Pasdeloup Grenez 2019). Besides, natural antioxidants are widely distributed in food and medicinal plants. These natural antioxidants, especially polyphenols and carotenoids, exhibit a wide range of biological effects, including anti-inflammatory, anti-aging, anti-atherosclerosis, and anticancer (Xu et al 2017).

The Zingiber officinale is often referred to as ginger, and it is one of the most widely used spices of medical value in the world (Pai Jakribettu et al 2016), it can be found in subtropical and tropical Asia, Far East Asia, China, India, and Africa (Mohd Sahardi and Makpol 2019), and is commonly used as a dietary complement to reduce nausea and vomiting. The Provisional preliminary evidence indicates that ginger may reduce the pain of dysmenorrhea and osteoarthritis, which is thought to be related to the antiinflammatory effects of gingerol and related compounds (Huang 2019). 
This experiment aimed to highlight functional and/or pathological alterations of abamectin and evaluate ginger's protective effect (Zingiber officinale) on hepatotoxicity.

\section{Materials and Methods}

\subsection{Animals}

We have chosen the basic biological material: the white rat Rattus of the Wistar strain, from Algiers' Pasteur Institute (Algeria). These animals have been acclimated to the animal room's conditions at a temperature of $25 \pm 2{ }^{\circ} \mathrm{C}$. The food brought to them has sticks and is made of corn, barley, milk, and vitamin supplements (Oued Fragha, Guelma city, Algeria). We chose forty (40) females according to weight (approximately 250 grams) which we separated into 5 experimental groups: Control lot (C) [n=8]: received physiological water ,Abamectine lot (ABM) [n=8], lot treated with Abamectine and ginger (ABM-Gi) [n=8], a nonAbamectine lot treated with ginger $(\mathrm{Gi})[\mathrm{n}=8]$, lot treated with Abamectine and olive oil (ABM-V) $[n=8]$, non-abamectin lot treated with olive oil $(V)[n=8]$. The rats were observed each day individually for 21 days.

\subsection{Chemicals}

Abamectin ( $\mathrm{ABM}$ ) belongs to the avermectin family. It is isolated from the fermentation of Streptomyces avermitilis (Dufaure 2012). The inhalation of abamectin (ABM) $18 \mathrm{~g} / \mathrm{l}$ of the brand VERTIMEC ${ }^{\circledR}$ of dose $5.04 \mathrm{mg} / \mathrm{l}$ (Pulce and Hermouet 2012), mixed with distilled water in groups (ABM), (ABM-Gi) and (ABM-V) was carried out by an ultrasound aerosol therapy device (Project 0470 ITALY), the latter consists in transforming the substances from the liquid form to the aerological form, allowing them to be nebulized directly in the respiratory system.

- Maximum capacity of the nebulizing sphere: $6.5 \mathrm{ml}$.

- Minimum capacity of the nebulizing sphere: $3 \mathrm{ml}$

\subsection{Ginger administration}

The Zingiber officinale (ginger) used for rats' treatment is a concentrated amber to brown liquid (SIGMA ALDRICH ginger extract natural FG 99\%). The corresponding dose preparation depends on the rats' weight, i.e., 3 milliliters per 1 kilogram of body weight. One mixes $1 \mathrm{ml}$ of olive oil per kilogram of body weight (in fact, olive oil has been mixed with ginger for a rapid and more remarkable effect). Agitation is mandatory to homogenize the solution before administration. Ginger treatment starts on the 11th day after inhalation of abamectin (ABM) and is administered by gastric gavage of rats for seven days (duration of treatment).

\subsection{Administration of olive oil}

The antioxidant (olive oil) chosen to treat female rats is found in the liquid form of golden yellow color from the Small Kabylie (Bejaia-Algeria). To prepare the adequate dose, a $10 \mathrm{ml}$ syringe with a metal feeding tube is used, and $1 \mathrm{ml}$ of olive oil is measured according to the rats' weight for $1 \mathrm{~kg}$ of body weight. Olive oil treatment is used for the ABM-V and V groups. The frequency and duration of administration are daily for seven days ( $11^{\text {th }}$ after inhalation of abamectin).

\subsection{The test of the open-field (OF)}

The open-field test, initially described by Hall in 1934, was developed to measure differences in emotional reactivity in rats. This test indicates locomotor activity and anxious behavior, respectively. The latter is all the more pronounced when the rat spends more time in the peripheral area. As for the central zone, its exploration represents a sign of less anxiety. (The test was applied on day 10 and 18) (Sáenz et al 2006).

\subsection{ALT/AST Transaminases, Alkaline phosphatase}

Liver transaminases (alanine transaminases, ALT; and aspartate transaminases, AST) are according to Murray and Kaplan (1984), and the protocol for alkaline phosphatase (ALP) activity is by Wenger and Kaplan (1984) and Yahia et al (2015).

\subsection{Statistical analysis}

The results were represented as a mean plus or minus the mean, standard deviation (Mean \pm SEM) (Standard error). The results were analyzed using one-way analysis of variance (ANOVA) followed by Tukey's test to compare the different treatment groups (biochemical parameters and body/liver weights). We used Student's t-test for the open-field test. The statistical analysis of the data was carried out using the GraphPad Prism (Version 6).

Differences are considered as significant, when $P<$ 0.05 ; very significant, when $P<0.01$; and highly significant, when $P<0.001$; where $P$ : significance level.

\section{Results}

\subsection{Evaluation of body weight and liver weight}

During the study period, in Figure 1, the rats' bodyweight was affected by abamectin (ABM). In fact, on day 10 , we observed that the abamectin (ABM) caused a nonsignificant decrease $(P>0.05)$ in the group of rats exposed to abamectin only (ABM) in animals treated with abamectin and ginger (ABM-Gi). Also, in toxic females treated with olive oil (ABM-V), the control (C) was compared: (C: 243.3 \pm 1.702 vs.

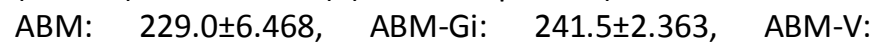
239.8 \pm 4.385$)$.

After the treatment, we noticed on days 13 and 18 a non-significant increase $(P>0.05)$ in the group (ABM-Gi) compared to the control group (C) and the olive oil-treated toxic group (ABM-V). In contrast, a non-significant decrease $(P>0.05)$ in the abamectin-contaminated females treated with olive oil (ABM-V) compared to the group (ABM-Gi). On the other hand, a very significant increase $(P<0.01)$ was observed in the group ( $V$ ) compared to the group (Gi). (ABMGi: $241.5 \pm 2.363$ vs C: $243.3 \pm 1.702$ and ABM-V: $239.8 \pm$ 
4.385), ( ABM-V: $239.8 \pm 4.385$ vs ABM-Gi: $241.5 \pm 2.363)$, (Gi: $246.5 \pm 2.500$ vs $\mathrm{V}: 251.8 \pm 2.780$ )

Results in Table 1 showed that there was a highly significant decrease $(P<0.001)$ in absolute liver weight in females exposed to abamectin only (ABM) compared to the control group (C), we note a very significant decrease $(P<$ 0.01 ) in females treated with abamectin and olive oil (ABM-
V) compared to the control group (C), a very significant reduction $(P<0.01)$ in the relative weight of the liver is observed in untreated toxic females compared to control groups (ABM), while a significant decrease $(P<0.05)$ is observed in toxic females treated with olive oil (ABM-V). The groups (ABM-Gi) and (Gi), (V) did not reveal any significant difference.

\section{Body weight (g)}

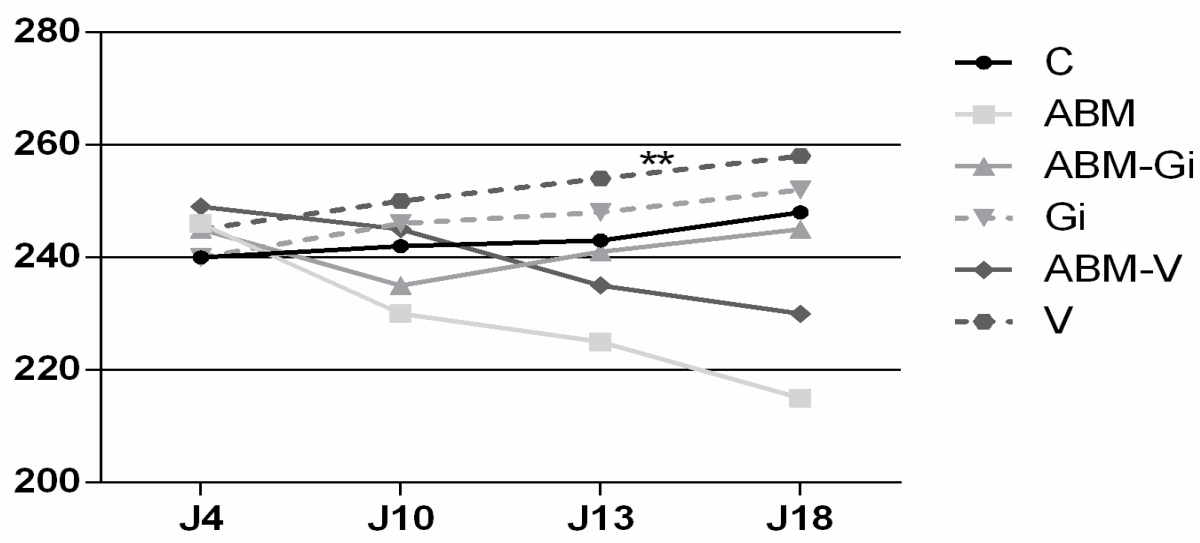

Figure 1 Weight change of rates. The results are expressed in Mean \pm SEM. Ns.: Difference not significant $(P>0.05) ;{ }^{*} P<0.05 ;{ }^{* *} P<0.01$; $* * * P<0.001)$.

Table 1 Variations in the relative and absolute weight of the liver in female control rats in groups exposed to Abamectin (ABM), treated with abamectin and ginger ( $\mathrm{ABM}-\mathrm{Gi})$, treated with abamectin and olive oil (ABM-V), intoxicated, and treated with ginger only (Gi) and intoxicated treated with olive oil just (V).

\begin{tabular}{|c|c|c|c|c|c|c|}
\hline \multirow[t]{3}{*}{ Parameters } & Control & ABM & ABM-Gi & $\mathrm{Gi}$ & ABM-V & $\mathrm{V}$ \\
\hline & $\mathrm{n}=8$ & $\mathrm{n}=8$ & $\mathrm{n}=8$ & $\mathrm{n}=8$ & $n=8$ & $\mathrm{n}=8$ \\
\hline & Mean \pm SEM & Mean \pm SEM & Mean \pm SEM & Mean \pm SEM & Mean \pm SEM & Mean \pm SEM \\
\hline Absolute weight of liver (g) & $8.06 \pm 0.27$ & $5.63 \pm 0.48^{* * * a}$ & $7.08 \pm 0.23$ & $8.48 \pm 0.31$ & $6.14 \pm 0.25^{* * a}$ & $7.71 \pm 0.37$ \\
\hline Relative weight of liver (g ) & $3.24 \pm 0.11$ & $2.77 \pm 0.10^{* * a}$ & $2.88 \pm 0.09$ & $3.23 \pm 0.18$ & $2.66 \pm 0.10^{* a}$ & $2.98 \pm 0.14$ \\
\hline
\end{tabular}

\subsection{Effect of different treatments on liver function parameters}

\subsubsection{Alanine aminotransferase (ALT)}

ALT (expressed in $U / L$ ) was measured on day 21 . Abamectin caused a very significant increase $(P<0.01)$ in female rats exposed to abamectin only (ABM) compared to the control group (C). Also, we observe a highly significant increase $(P<0.001)$ in female rats treated with abamectin and olive oil (ABM-V) compared to the control group (Figure 2).

However, ginger improved these values in the group treated with abamectin and ginger (ABM-Gi), which showed a highly significant decrease $(P<0.001)$ compared to the group (ABM-V). Our results show a highly significant increase $(P<0.001)$ in abamectin-exposed females treated with olive oil (ABM-V) compared to the non-toxic lot treated with olive oil (V). The groups (V) and (Gi) did not reveal any significant difference.

\subsubsection{Glutamo-oxaloacetic transaminase (GOT)/(AST)}

In Figure 3, the activity of AST showed a very significant $(P<0.01)$ increase in abamectin females rats (ABM). Also, a highly significant $(P<0.001)$ increase in females treated with abamectin and olive oil (ABM-V) compared to the group control (C). A very significant $(P<$ $0.01)$ decrease in the group treated with abamectin and ginger ( $A B M-G i)$ compared to the group (ABM-V).

A highly significant increase $(P<0.001)$ was observed in toxic animals treated with olive oil (ABM-V) compared to the non-abamectin lots treated with the same antioxidant (V). 


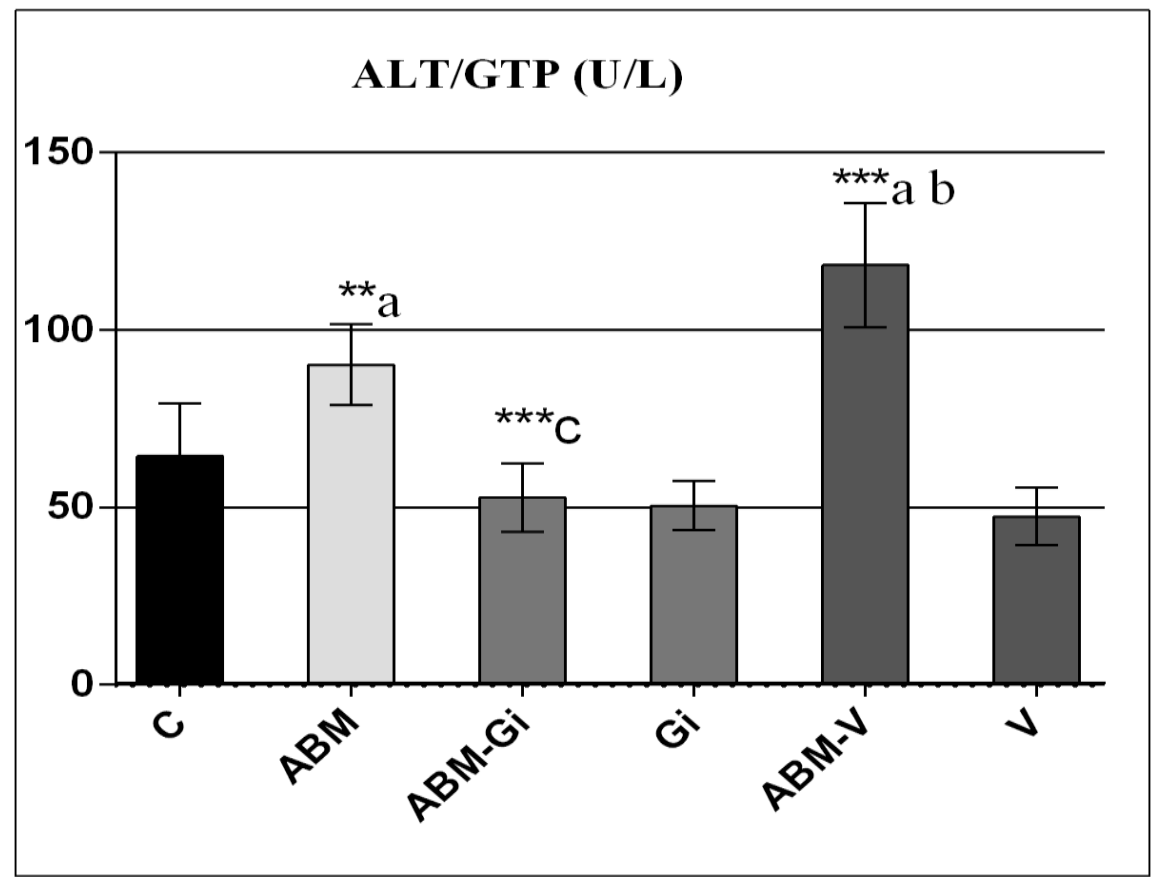

Figure 2 Variation in ALT/GTP U/L enzyme activity in female rats. Ns.: Difference not significant $(P>0.05) ;{ }^{*} P<0.05 ;{ }^{* *} P<0.01 ; * * * P<$ 0.001). a: Comparison between control and one of the lot ,b: Comparison between (ABM-GI) with (Gi) and (ABM-V) with (V), c: Comparison between (ABM-Gi) and (ABM-V).

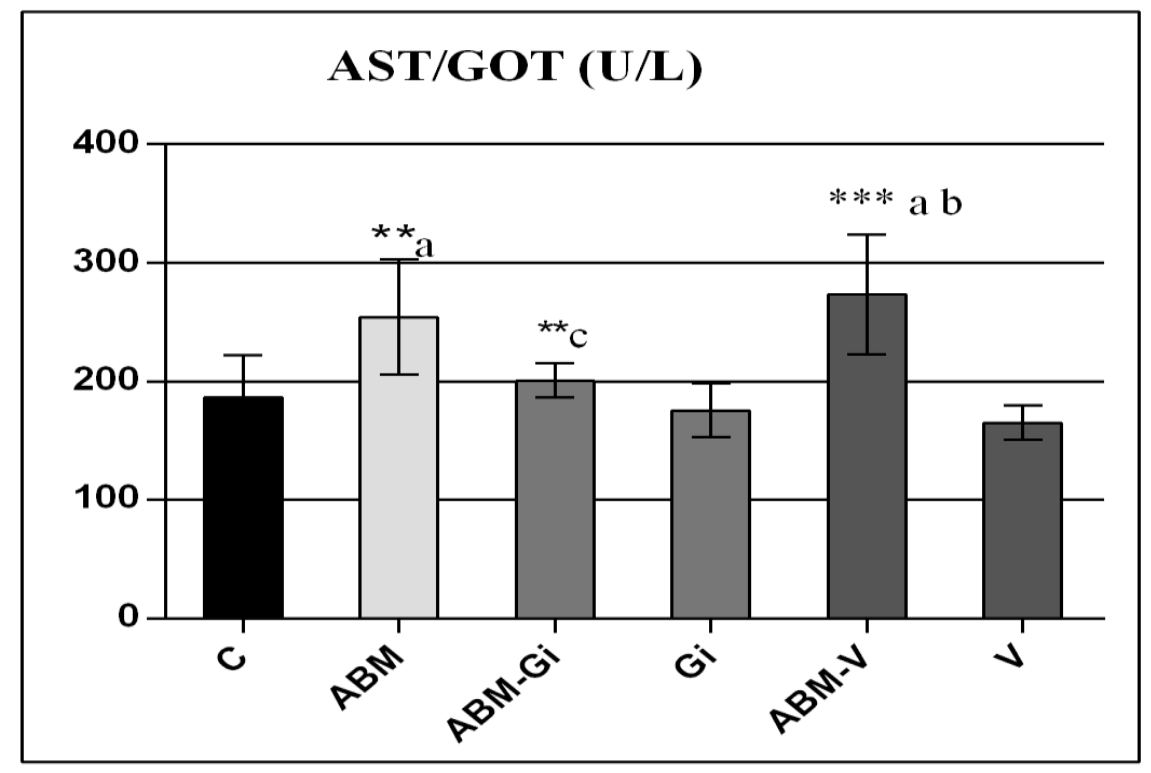

Figure 3 Variation in enzyme activity of AST/GOT U/L. Ns.: Difference not significant $\left.(P>0.05) ;{ }^{*} P<0.05 ; * * P<0.01 ; * * *<<0.001\right)$. a: Comparison between control and one of the lot,b: Comparison between (ABM-Gi) with (Gi) and (ABM-V) with (V), c: Comparison between (ABM-Gi) and (ABM-V).

\subsubsection{Alkaline phosphatase (ALP)}

In Figure 4, alkaline phosphatase levels (expressed in $U L / I)$ were measured on day 21 in the five rats groups and showed a highly significant increase $(P<0.001)$ in the toxic group untreated (ABM). Also, in the animals treated with abamectin and olive oil (ABM-V) compared to the control group (C).

The results obtained show a highly significant $(P<$ 0.001 ) increase in toxic females treated with ginger (ABM-Gi) compared to abamectin-exposed females treated with olive oil (ABM-V). Inhalation of abamectin caused a highly significant $(P<0.001)$ increase in female rats exposed to abamectin treated with olive oil (ABM-V) compared to group (V).

\subsection{Variation of the open field test parameters}

Figure 5 shows the different parameters of the open field test. The results obtained to show in figure $5 \mathrm{~A}$ a highly 
significant $(P<0.001)$ decrease in the distance traveled in the lot exposed to abamectin only (ABM), as well as in the female rats treated with abamectin and ginger (ABM-GI) it shows a highly significant $(P<0.001)$ decrease in a comparison between day 10 and day 18 . A significant decrease $(P<0.05)$ in the lot treated with ginger on day 10 compared to day 18 .

Concerning the second parameter (Figure 5B), which we observe a highly significant decrease $(P<0.001)$ in the abamectin-only lot (ABM) compared to day 18 . In rats treated with abamectin and ginger (ABM-Gi), a significant $(P<0.05)$ increase on Day 18 compared to Day 10 . A highly significant $(P<0.001)$ increase in the female rats treated with abamectin and olive oil (ABM-V) on day 18 compared to day 10. is the time spent in the peripheral area in figure $B$ on day 10 ,

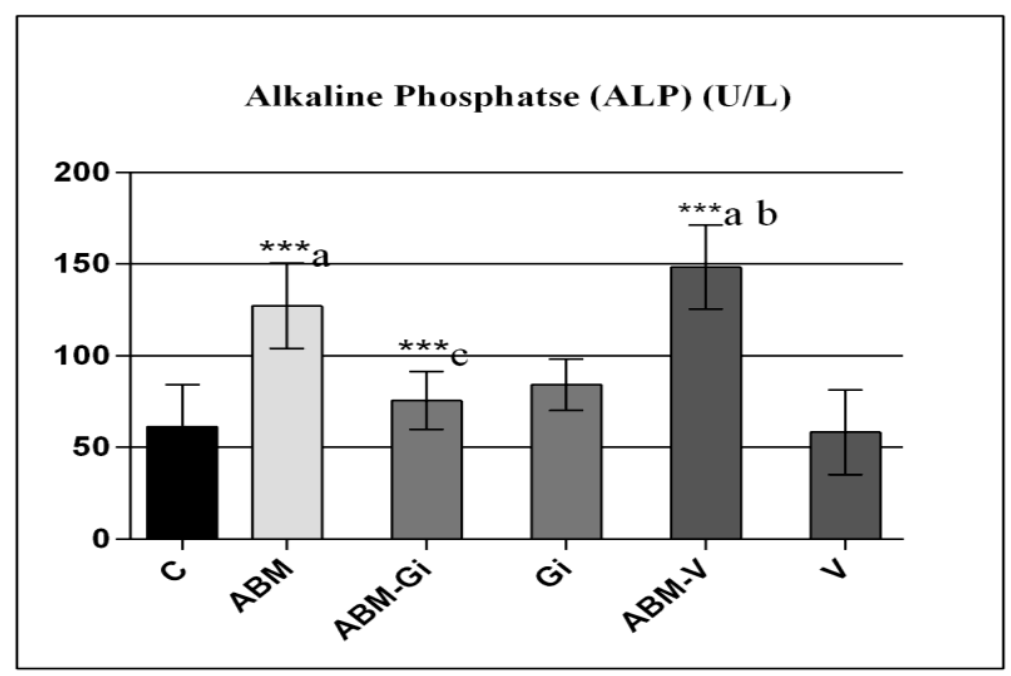

Figure 4 Variation in enzyme activity of Alkaline Phosphatase (ALP) U/L. Ns.: Difference not significant $(P>0.05) ; * P<0.05 ; * * P<0.01 ; * * * P$ $<0.001)$. a: Comparison between control and one of the lot, b: Comparison between (ABM-Gi) with (Gi) and (ABM-V) with (V), c: Comparison between (ABM-Gi) and (ABM-V).

\section{Discussion}

Pesticides are metabolized in the liver and are hypothesized to contribute to liver carcinogenesis through cell adhesion alterations, oxidative stress, genotoxicity, tumor promotion, immunotoxicity, and hormonal action (VoPham 2017). Inhalation of Abamectin caused hepatotoxicity, which indicates an increase in AST/ALT transaminases consistent with the results found by Beytullah Yildirim et al (2010) explain that elevated aminotransferase levels (ATLs) are alert the physicians for liver-affecting disease and may reflect liver injury. The leading causes of highly augmented aminotransferases in the serum, either from the destruction of tissue containing them or from changes in permeability membrane (Pariente 2013).

Alkaline PALs rise in cholestasis cases, hepatic insufficiency with reduced hepatocytes, and varied causes (Lienhardt-Roussiea et al 2017). It is an enzyme present in many tissues. It hydrolyses organic phosphates and releases insoluble mineral phosphates, which are essential for the calcification and mineralization of the skeleton and is also believed to play a role as a "transporter" of phosphate radicals and other substances (lipids and $\mathrm{Ca}$ in the intestine) (Chevrot 2007). During the study, The reduction in body weight gain is used as an indicator of toxicity and deterioration in rats' general health. This reduction may be due to the effect of pesticides on the gastrointestinal tract through the loss of appetite and/or poor absorption of food resulting in a reduction in food and water consumption in pesticide-treated rats (Venkateshwarlu et al 1997). The decrease in body weight might also be due to anorexia, i.e., a massive loss of fat and fat-free body masses (De Caprio et al 2005). Starvation causes hepatocyte injury and death, leading to a rise in aminotransferases; malnutrition-induced hepatitis is common among individuals with anorexia nervosa, especially as body mass index decreases( Rosen et al 2017).

Also, the results show a decrease in the relative and absolute weight of the liver compared to El-Gendy et al (2015), showed that there was a significant decrease in the body weight gain and an increase in the relative weights (gm/100 gm body weight) of the liver.

According to scientists, ginger is an integral part of traditional oriental cuisine and medicine. For centuries, its rhizome has been used to treat various diseases and Chinese and Ayurvedic medicine (Butin 2017). The hepatoprotective effect of ginger extract on many chemical and drug-induced liver lesions has been demonstrated in rat studies (Huang 2019). Which defines that Ginger products exert their antioxidant effect by quenching free radicals due to the development of polyphenol compounds (6-gingerols and their derivatives) ( Farag et al 2010). The group of female rats toxic supplemented with ginger (Zingiber officinale) in olive oil have a slight improvement in liver parameters (AST/ALT) as compared to the group control comparatively to Sakr (2007). These results show that treating rats with another pesticide (mancozeb) and ginger (mixed with distilled water) indicated ginger's effectiveness in preventing hepatotoxicity. 

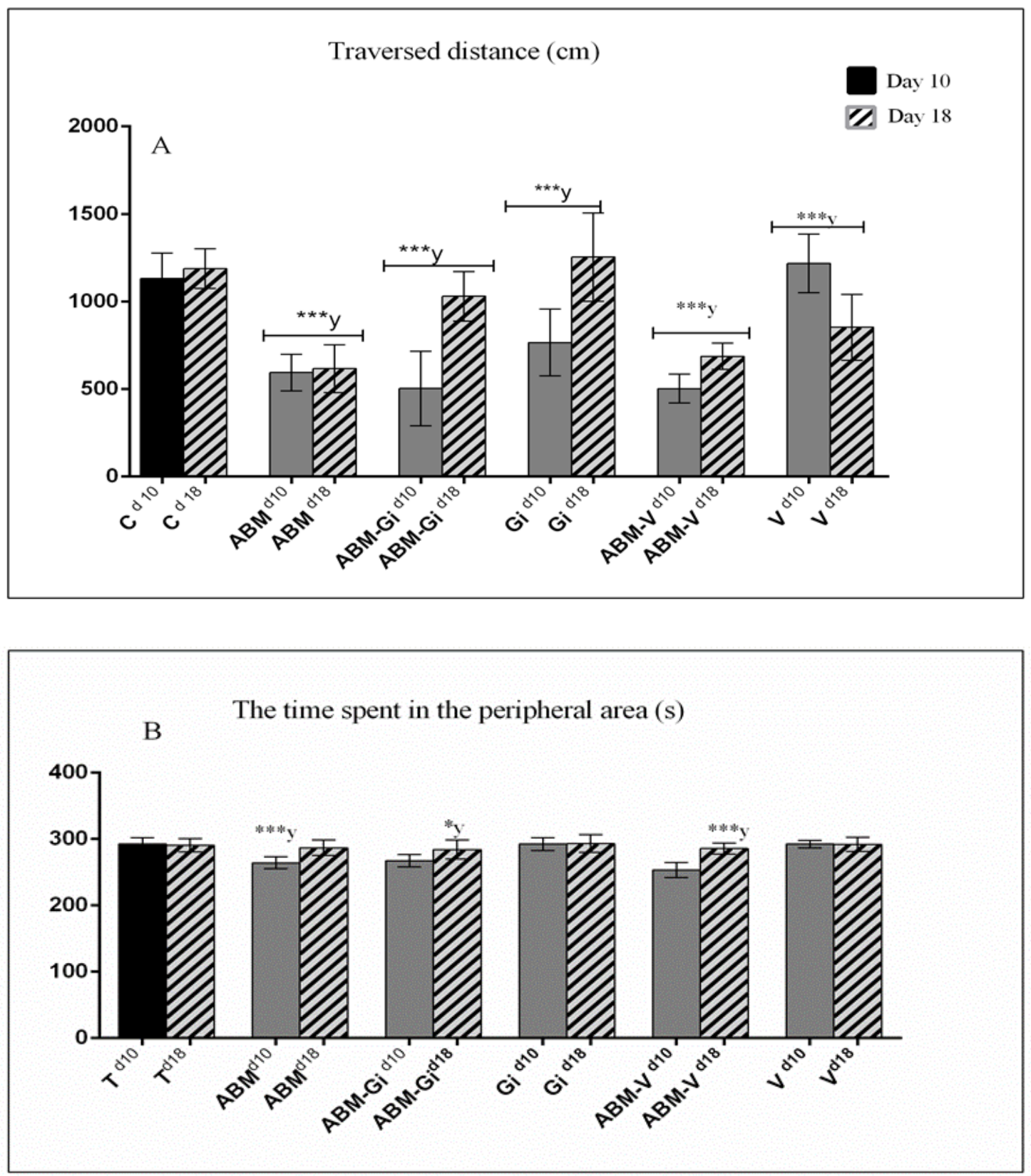

Figure 5 Variation in open field parameters in control female rats $(T)$, rats treated with Abamectin (ABM), rats treated with abamectin and ginger (ABM-Gi), rats treated with ginger only $(\mathrm{Gi})$, rats treated with abamectin and olive oil $(\mathrm{ABM}-\mathrm{V})$ and rats treated with olive oil just $(\mathrm{V})$. $A$ : Traversed distance $(\mathrm{cm})$ and $B$ : the time spent in the peripheral area $(\mathrm{s})$. Ns.: Difference not significant $(P>0.05) ;{ }^{*} P<0.05 ;{ }^{* *} P<0.01$; $* * * P<0.001)$.

Neurotoxicity is defined as a structural change or functional impairment of the nervous system, which originates from exposure to physical, biological, or chemical agents (Philbert et al 2000). In adults, it often involves peripheral jumpy system effects because the central nervous system (CNS) is well protected by the blood-brain barrier, which prevents the passage of many endogenous and exogenous toxic agents into the brain (Costa et al 2004). Our study showed that rats exposed to abamectin had depression, which means a highly significant decrease in test parameters (traversed distance and the time spent in the peripheral area). According to De Faria (2018), the open field test showed an anxiolytic response in birds exposed to abamectin.

These results contradict the work done by (Schmitt and Hiemke 1998; Prut and Belzung 2003), which states that the reduction in the distance traveled in the device in stressed rats indicates a decrease in exploratory activity characteristic of a higher level of anxiety in rats. Behavioral studies of animal models are of great importance as they allow the detection of different neurotoxicity forms.

Previous studies have shown that olive oil, which has anti-apoptotic, anti-inflammatory, and antioxidant properties, protects tissues from damage caused by oxidative 
stress (Mohammadian 2018). However, the present results demonstrated that the treatment of rats with olive oil showed a significant increase in liver parameters in female rats treated with abamectin comparatively with Nakbi1(2010). Several studies have demonstrated the ability of olive oil to inhibit oxidative stress in the liver.

Consequently, case reports and surveys from multiple regions worldwide show that acute pesticide poisonings, both occupational and non-occupational, continue to be a significant issue with mild-to-fatal effects. There is an urgent need for a valid global estimate (Blair et al 2014).

\section{Conclusions}

The link between pesticide exposure and health is difficult to establish. However, many epidemiological studies have raised the possible existence of pollutants' effect on the nervous system, behavioral disorders, and some hepatic diseases. For these reasons, the exploitation of the biological potential of plant species is of great interest. Hence, the new approaches consist of looking for active ingredients in natural products of plant origin. Our results confirm that Abamectin toxicity induces neurobehavioural disturbances accompanied by weight loss, decreased absolute and relative liver weight, and biochemical parameter changes. Besides, ginger's power as a reducer of oxidative stress is well demonstrated, and it also provides protection against the toxic effects of abamectin, and it acts as a significant hepatoprotective.

\section{Acknowledgments}

I want to thank the Applied Neuroendocrinology Laboratory and the whole team of the Biology Department, Annaba, Algeria.

\section{Conflict of Interest}

The authors declare no conflict of interest.

\section{Funding}

This research did not receive any financial support.

\section{References}

Blair A, Ritz B, Beane Freeman L, Wesseling C (2014) Pesticides and human health. Occupational and Environmental Medicine. doi: 10.1136/oemed2014-102454

Butin A (2017) Le gingembre : de son utilisation ancestrale à un avenir prometteur. Université de lorraine, France.

Chevrot $M(2007)$ Alkaline phosphatase. Medical Biology. doi: 10.1016/S0000-0000(06)47796-2

Costa LG, Aschner M, Vitalone A, Syversen T, Soldin OP (2004) Developmental Neuropathology of Environmental Agents. Annual Review of Pharmacology and Toxicology 44:87-110.

De Caprio C, Alfano A, Senatore I, Zarrella L, Pasanisi F and Contaldo F (2005) Severe acute liver damage in anorexia nervosa: two case reports. Nutrition. doi :10.1016/j.nut.2006.01.003

De Faria DBG, Montalvão MF, Chagas TQ, Araújo APDC, de Souza JM, Mendes BO, Rodrigues ASL, Malafaia G (2018) Behavioral changes in Japanese quails exposed to predicted environmentally relevant abamectin concentration. Science of The Total Environment 636: 1553-1564
Dufaure C (2012) INSECTICIDE ET SANTE HUMAINE : Aspect toxicologiques, épidémiologiques et juridiques .thèse de doctorat, Université de Limoges ,France.

El-Gendy KS, Aly NM, Mahmoud HF, Abd Allah DM, Abdel El Sebae AKH (2015) Hepatotoxicity and Nephrotoxicity in Mice Induced by Abamectin and Ameliorating Effect of Quercetin. Asian Journal of Agricultural and Food Sciences 3: $2321-1571$.

Farag AGA, Elhalwagy MEA, Farid HEA (2010) Effect of ginger supplementation on developmental toxicity induced by fenitrothion insecticide and/or lead in albino rats. Pesticide Biochemistry and Physiology. doi: https://doi.org/10.1016/j.pestbp.2010.03.007

Hall CS (1934) Emotional behavior in the rat. Defeacation and urination as measures of individuel difference in emotionality. Journal of Computational Physics 18, 385-403.

Huang YS (2019) The hepatoprotective effect of ginger. Journal of the Chinese Medical Association 82(11): 805-806. doi: 10.1097/JCMA.0000000000000174

Jargot D, Falcy M , Robert S ,Angeli k Fastier A, Rambourg MO (2013) Fiches toxicologiques (Abamectin).$n^{\circ} 299$ INRS ,France.

Khaldoun-Oularbi H, Richeval C, Djenas N, Lhermitte M, Humbert L, Baz A (2013) Effect of sub-acute exposure to abamectin (insecticide) on liver rats (Rattus norvegicus). Annales de Toxicologie Analytique 25(2): 63-70.

Lasota J A, Dybas R A (1990) Abamectin as a pesticide for agricultural use. Acta Leiden 59(1-2): 217-25.

Lienhardt-Roussie A, Simonin G (2017) ALKALINE PHOSPHATASE ANOMALIES. PEDIATRICS ARCHIVE 19:10-11.

Mohammadian M, Mianabadi M, Zargari M, Karimpour A, Khalafi M, Amiri FT (2018) Effects of Olive Oil supplementation on Sodium Arsenate-induced Hepatotoxicity in Mice. International Journal of Preventive Medicine 9: 59.

Mohd Sahardi NFN, Makpol S (2019) Ginger (Zingiber officinale Roscoe) in the Prevention of Ageing and Degenerative DiseasesReview of Current Evidence. Evidence-Based Complementary and Alternative Medicine (3):113.

Murray R, Kaplan A et al (1984a) Aspartate aminotransferase. Clinical chemistry. Toronto, Canada: The C.V. Mosby Co. St Louis. Princeton: 1112 1116 .

Murray R, Kaplan A et al (1984b) Alanine aminotransferase. Clinical chemistry. Toronto, Canada: The C.V. Mosby Co. St Louis. Princeton Princeton: 1088-1090.

Nakbi A, Tayeb W, Grissa A, Issaoui M, Dabbou S, Chargui I, Ellouz M, Miled A, Hammami M (2010) Effects of olive oil and its fractions on oxidative stress and the liver's fatty acid composition in 2,4Dichlorophenoxyacetic acid-treated rats . Nutrition \& Metabolism. doi: 10.1186/1743-7075-7-80

Niroumand MC, Farzaei MH, Razkenari Ek, Amin G, Khanavi M , Akbarzadeh T, Shams-Ardekani MR ( 2016) An Evidence-Based Review on Medicinal Plants Used as Insecticide and Insect Repellent in Traditional Iranian Medicine. Iranian Red Crescent Medical Journal. doi: 10.5812/ircmj.22361

Organisation Mondiale de la santé (1991) L'utilisation des pesticides en agriculture et ses conséquences pour la santé publique .Genève, Suisse.

Pai Jakribettu P, Boloor R, Bhat PH, Thaliath A, Haniadka R, Rai M, George T, Baliga S (2016) Ginger (Zingiber officinale Rosc.) Oils. In: Victor R. Preedy (editor). Essential Oils in Food Preservation, Flavor and Safety. London, UK: Academic Press (Verlag), pp. 447-454.

Pariente A (2013) Cytolyse hepatique (augmentation des aminotransferases) chez l'adulte. HEPATO-GASTRO et Oncologie digestive (20) 8 : 630-639.

PASDELOUP GRENEZ E (2019) Phytothérapie - exemples de pathologies courantes à l'officine :Fatigue, Insomnie, Stress, Constipation, Rhume,Douleur et Inflammation. thése de dcotorat, Université de Lille ,France.

Philbert MA, Billingsley ML, Reuhl KR (2000) Mechanisms of injury in the central nervous system. Toxicologic Pathology 28:43-53. 
Prut L, Belzung C (2003) The open field as a paradigm to measure the effects of drugs on anxiety-like behaviors: a review. European Journal of Pharmacology 463:3.

Pulce C, Hermouet C (2012) Abamectine : étude rétrospective des expositions aux produits phytopharmaceutiques à base d'abamectine recueillies par les Centres antipoison et de toxico vigilance (CAPTV) et le Réseau Phyt'attitude de la Mutualité Sociale Agricole (MSA) entre 1999 et 2012. Lyon, France

Rosen E, Bakshi N, Watters A, Rosen RH, Mehler PS (2017) Hepatic Complications of Anorexia Nervosa. Digestive Diseases and Sciences 62(11):2977-2981.

Sáenz, JCB., Villagro OR, Trias JF ( 2006) Factor analysis of Forced Swimming test, Sucrose Preference test and Open Field test on enriched, social and isolated reared rats. Behavioural Brain Research 169:57-65.

Sakr S (2007) Ameliorative Effect of Ginger (Zingiber officinale ) on Mancozeb Fungicide Induced Liver Injury in Albino Rats. Australian Journal of Basic and Applied Sciences 1(4): 650-656.

Samuel O, Saint-laurent L (2001) Guide de préventions pour les utilisateurs de pesticide en agriculture maraaichére. Québec,Canada.

Schmitt U, Hiemke C (1998) Combination of open field and elevated plusmaze: a suitable test battery toassess strain as well as treatment differences in rat behavior. Progress in Neuro Psychopharmacology \& Biological Psychiatry 22: 1197-1215.

Shaban S, Abdou BKH, Hassan NEHY (2015) Impact of toxic heavy metals and pesticide residues in herbal products. Beni-Suef University Journal of Basic and Applied Sciences 5(1): 102-106.
ValléeK M, Margo. W, Delh F, Le Moal M., (1997) Prenatal stress induces High anxiety and Postnatal handling induces low anxiety in adult offspring: correlation with stress induced corticosterone secretion. Journal of Neuroscience 17:2626-2636.

Venkateshwarlu, P, Sharma BJR, Kalakumar B, Reddy KS, Ravikumar $\mathrm{P}(1997)$ Comparative evaluation of toxicity of carbaryl, cypermethrin and malathion of testis in mice. Indian J Toxicol 4: 33-37.

VoPham T, Bertrand KA, Hart JE, Laden F, Brooks MM, Yuan JM, Talbott EO, Ruddell D, Chang CCH, Weissfeld JL (2017) Pesticide exposure and liver cancer: a review. Cancer Causes Control 28(3): 177-190.

Wenger C, Kaplan A et al. (1984). Alkaline phosphatase. Clinical chemistry. Toronto, Canada: 1094-1098.

Xu DP, Li Y, Meng X, Zhou T, Zhou Y, Zheng J, Zhang JJ, Li HB (2017) Natural Antioxidants in Foods and Medicinal Plants: Extraction, Assessment and Resources. International Journal of Molecular Sciences 18(1): 96.

Yahia E, Aiche MA, Chouabbia A, Boulakoud MS (2015) Biochemical and Hematological Changes Following Long Term Exposure to Mancozeb.Advances in Bioresearch 6 (2): 83-86.

Yildirim B, Ozugurlu F, Sahin S, Ozyurt H, Atis O, Kbas A, Aktürk Y, Ozdemir M Sahin I, Bulut Y, Etikan Y, Firat MM (2010) Association between elevated aminotransferase levels and the metabolic syndrome in Northern Turkey. Annals of Hepatology 9:161-5. 